\title{
LOCUÇÃO E AUDIODESCRIÇÃO NOS ESTUDOS DE TRADUÇÃO AUDIOVISUAL
}

\section{LOCUTION AND AUDIO DESCRIPTION IN AUDIOVISUAL TRANSLATION STUDIES}

\author{
Wilson Júnior de Araújo Carvalho* \\ Bruna Alves Leão** \\ Charleston Teixeira Palmeira***
}

\section{RESUMO}

Neste texto, a audiodescrição é considerada uma modalidade de tradução audiovisual utilizada como recurso de acessibilidade para pessoas com deficiência visual. Desse modo, com base nos Estudos de Tradução Audiovisual, tivemos por objetivo descrever e analisar os resultados de três estudos sobre locução na audiodescrição. As análises realizadas revelam que a locução na audiodescrição ainda necessita ser trabalhada principalmente com relação às variáveis uso da ênfase, curva melódica e ritmo, para que a locução possa ser aperfeiçoada e para que possamos propor parâmetros que auxiliem os audiodescritores a aprimorarem sua voz/fala de forma profissional e condizente com a obra audiodescrita, seja na locução na audiodescrição de filmes ou de peças teatrais.

Palavras-chave: audiodescrição no teatro; audiodescrição de filmes; acessibilidade audiovisual.

\section{ABSTRACT}

In this text, audio description is considered an audiovisual translation modality used as an accessibility resource for people with visual impairment. Thus, based on the Audiovisual Translation Studies, we aimed to describe and analyze the results of three studies on voiceover in audio description. The analysis reveal that the locution in the audio description needs improvement, mainly in the following variables: use of the emphasis, melodic curve and rhythm. Starting from this improvement, we can propose parameters that help audiodescriptors to perfect their voice/speech in a professional way, and according to the audio described work, being that the voiceover for the audio description of films or plays. Keywords: audio description in theaters; audio description of films; audiovisual accessibility.

\section{INTRODUÇÃO}

$\mathrm{O}$ presente artigo tem como objetivo descrever e analisar os resultados de três estudos sobre locução na audiodescrição (doravante AD). O primeiro estudo,

\footnotetext{
* Universidade Estadual do Ceará, Fortaleza, CE. Brasil. wilson.carvalho@uece.br.

** Universidade Estadual do Ceará, Fortaleza, CE. Brasil. b.matilde@hotmail.com.

*** Universidade de Fortaleza, Fortaleza, CE. Brasil. chpalmeira@gmail.com.
} 
desenvolvido por Carvalho, Araújo e Magalhães (2013), trata sobre a locução na audiodescrição de filmes; o segundo, diz respeito aos resultados do projeto "A locução na audiodescrição para pessoas com deficiência visual: uma proposta para a formação de audiodescritores - LOAD" (ARAÚJO; CARVALHO; PRAXEDES FILHO, 2013), que analisa trechos de locuções na audiodescrição dos filmes Uma Vela para Dario e Entrevista; e o último, desenvolvido por Leão (2017), que se encontra em andamento, analisa a locução na audiodescrição no teatro.

\section{TRADUÇÃO AUDIOVISUAL E AUDIODESCRIÇÃO}

A audiodescrição é uma modalidade de tradução audiovisual que se constitui como um recurso de acessibilidade que atende prioritariamente às necessidades das pessoas com deficiência visual (doravante $\mathrm{PcDV}$ s). A AD consiste na descrição das informações apreendidas visualmente, que não estão contidas nos diálogos, nem nos efeitos sonoros de uma produção audiovisual, tornando a mesma acessível para quem não enxerga.

Cabe destacar que atualmente a $\mathrm{AD}$ vem sendo explorada por diversos campos de estudo, como a Ciência da Computação, a Comunicação, a Psicologia, dentre outros, contudo optamos pelo caminho da tradução em função do viés da afiliação linguística.

Ao direcionarmos o foco para o campo linguístico, a $\mathrm{AD}$ está incluída na disciplina Estudos da Tradução com base em Jakobson (1995), que identifica três tipos de tradução: a interlinguística (entre línguas diferentes), a intralinguística (dentro da mesma língua) e a intersemiótica (entre meios semióticos diferentes, constituindo a interpretação dos signos verbais por meio de sistemas de signos não-verbais).

Plaza (1987) amplia o conceito de Jakobson (1995) ao definir a tradução intersemiótica como uma operação na qual um texto pertence a um sistema de signos (verbal, visual, sonoro, etc.) que pode ser traduzido para outro sistema de signos. A AD ainda se afilia aos estudos da Tradução Audiovisual Acessível (TAV-a) (JIMENEZ, 2007), juntamente com a LSE (Legendagem para surdos e ensurdecidos).

Contudo, a AD só foi incluída nos Estudos da Tradução, como modalidade de Tradução Audiovisual (TAV), por Gambier (2003, 2004). Segundo o autor, a AD foi lançada no início de 1980 para descrever ações, expressões faciais, gestos, movimentos corporais, cores para cegos e PcDVs, através de uma trilha sonora. 
Segundo Franco e Araújo (2011), as leis de acessibilidade para o audiovisual do novo século forçaram um novo cenário no campo da TAV, a partir daí novos recursos foram pensados para tornar a comunicação acessível para as pessoas com deficiência visual e auditiva. Foi aí que surgiu a legendagem para surdos e ensurdecidos (LSE) e, posteriormente, a audiodescrição (AD) para PcDVs. É nesse novo cenário que ganham relevo as pesquisas sobre a locução na audiodescrição, considerando a importância daquela para o aprimoramento desta.

\subsection{Locução na audiodescrição}

Diversos estudos destacam a importância da locução na AD (CASADO, 2007; MATAMALA, 2007; JIMENEZ-HURTADO, 2007; BENECKE, 2004; SNYDER 2008; SILVA, 2009; SANTIAGO, 2015), contudo não especificam de que forma a voz deve ser trabalhada na $A D$, nem como o audiodescritor deve preparar a sua voz para que a mesma se alinhe com a produção que está sendo audiodescrita e consiga atender às expectativas das PcDVs.

Em Carvalho, Magalhães e Araújo (2013), temos o início de uma pesquisa descritivo-exploratória, que propõe identificar os aspectos da qualidade de voz e dos recursos de voz utilizados por audiodescritores, com o intuito de propor um programa de aprimoramento das habilidades de locução de AD para filmes. Esta pesquisa apresentou alguns dados preliminares, colhidos a partir de três locuções de audiodescritores do Grupo LEAD da UECE e de cinco locuções de estudantes de mestrado e de doutorado, que participaram da oficina "A Locução em Audiodescrição: neutralidade ou interpretação?", ocorrida durante o Colóquio Interinstitucional UFMG/UECE, em 2011. Na ocasião, os estudantes participantes desenvolviam pesquisas no campo da $\mathrm{AD}$ no Brasil.

Os primeiros resultados da pesquisa de Carvalho, Magalhães e Araújo (2013) apontaram para uma necessidade de estudos relacionados à qualidade vocal e aos recursos vocais, a fim de delimitar as habilidades necessárias ao audiodescritor no campo da locução da AD. Esses resultados foram o ponto de partida para as atividades desenvolvidas pelo projeto "A locução na audiodescrição para pessoas com deficiência visual: uma contribuição à formação de audiodescritores - LOAD" (ARAÚJO; CARVALHO; PRAXEDES FILHO, 2013).

O LOAD teve como objetivo propor parâmetros sistemáticos para orientar futuros audiodescritores a realizarem a locução na audiodescrição. Foram analisadas as locuções de ADs dos filmes "Uma Vela para Dario" e "Entrevista", à luz dos estudos de TAV, da Fonética, da Fonologia e da Fonoaudiologia e, a partir dele, foi 
desenhada uma primeira proposta de treinamento para audiodescritores para fins de aprimoramento da locução.

Durante algum tempo, sobretudo no início das práticas em AD no Brasil, convencionou-se que a locução deveria ser "neutra", sob a prerrogativa de que a mesma poderia influenciar no entendimento das PcDVs e que de alguma forma ela poderia interferir em sua fruição.

De acordo com Snyder (2008), as interpretações subjetivas devem ser evitadas, pois a interpretação deve ser feita pelo público-alvo. Ele afirma ainda que, além das competências linguísticas, o audiodescritor deve dominar as pausas, a entoação, as técnicas vocais e de locução e de interpretação oral e discursiva. Como podemos perceber, Snyder (2008) estabelece uma relação entre a interpretação e a locução, ou seja, segundo ele, as inflexões da voz podem denotar uma interpretação do audiodescritor sobre a obra e interferir no entendimento do espectador cego.

Um "babitus vocal" foi criado para a locução da AD a partir da prática e de normas criadas juntamente com o seu advento. No Brasil, a AD começou a partir da reprodução prática do que estava sendo feito na Europa. Segundo Barros Filho (2005), "todo habitus - e o habitus vocal não se discrimina - é um tipo de saber prático, ou seja, de conhecimento voltado para a ação, para a práxis, para o uso efetivo da voz". Ainda segundo o autor, "a observação repetida de uma situação de determinada natureza pode produzir no agente social uma reação - de manifestação vocal - espontânea não refletida". E assim cristalizou-se um modelo de locução de AD "neutra". Contudo, sabemos que é impossível uma locução ser neutra, pois as nossas escolhas tradutórias são influenciadas pelo nosso entendimento de mundo, pelas nossas vivências e pelas as nossas experiências, o que refletirá diretamente na forma como transmitimos as informações por meio da voz.

Somente por meio das pesquisas é que foi possível testar, refletir e questionar essa prática, contudo, ressalto que, até mesmo no início das pesquisas no Brasil, os principais grupos de pesquisa adotaram tal prática e, durante algum tempo, a locução da $\mathrm{AD}$ foi considerada como elemento de menor importância dentro do processo tradutório.

Essa questão sobre neutralidade, interpretação e expressividade ainda é pouco consensual no âmbito da $\mathrm{AD}$, sobretudo no que diz respeito à voz. Contudo já há quem, assim como nós, pense um pouco diferente. De acordo com Farias e Neves (2014),

[...] a audiodescrição é uma reconstrução ativa e criativa, porquanto envolve a tradução dos signos imagético e sonoro em escrito e falado. A audiodescrição realiza a interpretação da imagem, transmutando-a para a verbalização. Esse ato de interpretar define os contornos de uma realização, coloca em jogo o modo como o tradutor leu a obra e suas contribuições 
enquanto portador de uma experiência/conhecimento. (...) Neste caso, interpretar para a $\mathrm{AD}$ consiste em traduzir o plural embutido em cada imagem de forma reveladora, propiciando o alcance à informação, às expressões, a conteúdos, à conjugação de conhecimentos, além de evocar emoções, sentimentos e sensações geradas pela imagem. (FARIAS, NEVES, 2014, p. 82 , grifo nosso)

Sendo a AD uma reconstrução ativa e criativa, que coloca em jogo as contribuições e as experiências/conhecimento do audiodescritor, capaz de evocar emoções, sentimentos e sensações através da voz, como pode tal experiência ser neutra? De que forma o audiodescritor se distancia da expressividade reproduzida através da sua fala? Segundo Madureira (2005, p.16), "toda fala é expressiva, no sentido de que alguma forma de atitude, emoção, crença, estado físico ou condição social é veiculada por meio da fonação e da articulação dos sons".

Com relação à $\mathrm{AD}$ para o teatro, alguns autores defendem algumas estratégias. Matamala (2007) afirma que a narração da AD de uma obra teatral é realizada ao vivo, mas seu roteiro é feito com antecedência. Desta forma, mesmo com a dificuldade em se trabalhar com uma obra ao vivo, temos a possibilidade de planejar o seu roteiro e também a sua locução, o que contribui sobremaneira com a preparação da expressividade da locução do audiodescritor em produções como esta.

Ainda, segundo Matamala (2007), uma característica importante deste tipo de $\mathrm{AD}$ é que o roteiro e a locução sejam realizados pela mesma pessoa. Um dos motivos é a necessidade de sincronismo entre a locução do roteiro com o desenrolar de cada cena, para o caso de acontecer alguma improvisação por parte dos atores, fato corriqueiro no teatro. Tal fenômeno raramente acontece com a AD gravada, como no caso do cinema, do DVD e da televisão, posto que é possível refazer a gravação da $\mathrm{AD}$.

Entretanto, nem sempre é possível que o locutor audiodescritor seja o mesmo que elaborou o roteiro, daí a importância de uma preparação prévia com o locutor audiodescritor para que seja verificado o ritmo, a entoação, as pausas e as intenções do roteiro de AD. Vale ressaltar que, no caso do teatro, o locutor audiodescritor também deve estar familiarizado com o universo das artes cênicas, favorecendo o desenvolvimento, tanto do estudo da obra e da elaboração do roteiro, como do acompanhamento e da locução simultânea à evolução do espetáculo.

Palmeira, Araújo e Carvalho (2016), em seu último artigo, afirmam que os locutores são reconhecidos de acordo com o formato de atividade que exercem. $\mathrm{O}$ audiodescritor estaria inserido na categoria "locutor em geral" que divulga acontecimentos em geral. Sendo assim, ainda não temos um "formato" para esse tipo de locução, mas, a partir da prática e das pesquisas já realizadas, vislumbramos 
uma locução que dialogue com a obra audiodescrita, a qual transmite ao espectador com deficiência visual as nuances e emoções da obra.

Para cada audiodescrição um timbre de voz, uma entoação, uma emoção diferente, é assim que pretendemos trabalhar a locução dentro da AD. De acordo com Madureira (2005, p.16), "um tom ascendente pode ser interpretado pelos ouvintes como indicador de continuidade do discurso e criar expectativas sobre o que o falante irá dizer na sequência da fala". Portanto, acreditamos que por meio de recursos como este conseguiremos tornar a locução de $\mathrm{AD}$ algo mais prazeroso e condizente com a proposta da obra, seja ela gravada ou ao vivo.

Sendo assim, a partir da comparação das análises dos resultados de três diferentes estudos sobre locução na audiodescrição, tentaremos identificar os principais aspectos comuns a essas locuções, levando em consideração as peculiaridades de uma delas, a qual se consolidou na modalidade ao vivo.

As variáveis analisadas nos três estudos analisados neste artigo, a saber, fonação, ressonância, pitch, loudness, articulação, velocidade de fala, coordenação pneumofonoarticulatória (CPFA) e ataque vocal, são empregadas conforme Behlau, Madazio, Feijó e Pontes (2001), Cassol, Behlau e Madureira (2001) e em Behlau, Feijó, Madazio, Rehder, Azevedo e Ferreira (2005). Para fins de análise, foi utilizado um protocolo de avaliação perceptual-auditiva da locução, adaptado de protocolos de avaliação de voz da área de fonoaudiologia (KYRILLOS, 2003) e de fonética (LAVER, 1980).

\section{ESTUDO 01: LOCUÇÃO EM FILMES AUDIODESCRITOS PARA PESSOAS CEGAS OU COM BAIXA VISÃO: UMA CONTRIBUIÇÃO À FORMAÇÃO DE AUDIODES- CRITORES}

A primeira pesquisa, desenvolvida por Carvalho, Araújo e Magalhães (2013), de cunho descritivo-exploratório, identificou os aspectos da qualidade de voz e dos recursos de voz utilizados por audiodescritores, com o intuito de propor um programa de aprimoramento das habilidades de locução de $\mathrm{AD}$ para filmes. Esta pesquisa apresentou alguns dados preliminares, colhidos a partir de três locuções de audiodescritores do Grupo Legendagem e Audiodescrição (doravante LEAD) da UECE e de cinco locuções de estudantes de mestrado e de doutorado do país.

A análise deste primeiro estudo traz os resultados da avaliação perceptual das locuções, quanto à qualidade vocal e aos recursos vocais, a partir de dois corpora, considerando os ajustes de voz/fala empregados pelos audiodescritores. O corpus 1 traz as locuções da AD do filme "Águas de Romanza", realizadas por três 
integrantes do LEAD e o corpus 2 traz as cinco locuções da AD do videoclipe "Pop! Goes My Heart" do filme "Music and lyrics". Esta análise foi realizada por três juízes fonoaudiólogos que trabalham com a estética da voz, conforme apresentamos no Quadro 1.

Quadro 1. Qualidade vocal dos informantes do estudo 01 (corpus 1), segundo a avaliação dos juízes.

\begin{tabular}{|c|c|c|c|}
\hline Variáveis & $\begin{array}{c}\text { Ajustes empregados pelo } \\
\text { Inf. } 1\end{array}$ & $\begin{array}{c}\text { Ajustes empregados } \\
\text { pelo Inf. } 2 \\
\end{array}$ & $\begin{array}{c}\text { Ajustes empregados } \\
\text { pelo Inf. } 3 \\
\end{array}$ \\
\hline Fonação & $\begin{array}{l}\text { Predominantemente } \\
\text { modal, ainda que com } \\
\text { traços de aspereza e } \\
\text { soprosidade. }\end{array}$ & $\begin{array}{l}\text { Predominantemente } \\
\text { modal, mas com alguns } \\
\text { traços de soprosidade. }\end{array}$ & $\begin{array}{l}\text { Predominantemente } \\
\text { modal, com traços de } \\
\text { soprosidade. }\end{array}$ \\
\hline Ressonância & $\begin{array}{l}\text { Ajustes esperados para a } \\
\text { qualidade vocal normal. }\end{array}$ & $\begin{array}{l}\text { Dentro dos limites da } \\
\text { normalidade. }\end{array}$ & Hipernasal. \\
\hline Pitch & $\begin{array}{l}\text { Médio - "voz jovial para o } \\
\text { teor dramático do filme". }\end{array}$ & $\begin{array}{l}\text { Dentro dos limites da } \\
\text { normalidade. }\end{array}$ & $\begin{array}{c}\text { Médio - levemente } \\
\text { agudo. }\end{array}$ \\
\hline Loudness & Médio & $\begin{array}{l}\text { Fraco, a locução perde } \\
\text { força ao final do filme. }\end{array}$ & Médio. \\
\hline Articulação & $\begin{array}{l}\text { Necessita ser melhor } \\
\text { trabalhada, a narração } \\
\text { tende a ser imprecisa ao } \\
\text { final das frases. }\end{array}$ & Imprecisa. & Precisa. \\
\hline Velocidade de fala & $\begin{array}{l}\text { Média, precisa ser } \\
\text { aperfeiçoada por meio de } \\
\text { treinamento vocal. }\end{array}$ & Acelerada. & Média. \\
\hline CPFA & $\begin{array}{l}\text { Ajustes esperados para a } \\
\text { qualidade vocal normal. }\end{array}$ & $\begin{array}{l}\text { Dentro dos limites da } \\
\text { normalidade. }\end{array}$ & Adequada. \\
\hline Ataque Vocal & $\begin{array}{l}\text { Isocrônico, precisa ser } \\
\text { aperfeiçoada por meio de } \\
\text { treinamento vocal. }\end{array}$ & $\begin{array}{l}\text { Dentro dos limites da } \\
\text { normalidade. }\end{array}$ & Brusco. \\
\hline
\end{tabular}

Fonte: Adaptado de Carvalho, Araújo e Magalhães (2013).

Cabe destacar que, para a avaliação de cada variável, foi considerada representativa a avaliação consensual de, pelo menos, dois juízes, sendo assim, se a avaliação do terceiro juiz tiver sido discordante, ela foi eliminada. A partir da avaliação dos juízes fonoaudiólogos, percebemos que todos os informantes 
apresentam uma fonação modal ${ }^{1}$ com traços de soprosidade, o que pode ser reflexo de um possível mau uso do microfone ou uma ausência de familiaridade com o recurso. Apenas o informante 3 apresentou problemas com a ressonância e esta precisa ser trabalhada a partir de um aperfeiçoamento vocal.

O pitch nos revela que tipo de voz é a mais indicada para a obra, geralmente as vozes com pitch grave são mais indicadas para dramas, por exemplo. Segundo a avaliação dos juízes, tivemos problemas de pitch com os informantes 1 e 3 , os quais apresentaram pitch destoante para a obra audiodescrita. Sendo assim, ressaltamos a importância da escolha de uma voz com o pitch apropriado, que dialogue com a temática da obra a ser audiodescrita.

Com relação ao loudness, apenas o informante 2 apresentou um loudness fraco, sobretudo ao final das frases. Isso pode ter ocorrido em função da respiração do audiodescritor, o qual chegaria ao final das frases com pouca reserva de ar; ou ainda em função de uma grande quantidade de texto para ser executada em um curto espaço de tempo. O fato é que um loudness fraco pode inclusive comprometer o entendimento da AD por parte das PcDVs.

Dois dos informantes (Inf. 1 e Inf. 2) precisam trabalhar melhor a articulação, todos eles precisam ajustar a velocidade da fala (ainda que dois tenham uma velocidade média), dois deles (Inf.1 e Inf. 3) precisam aperfeiçoar o ataque vocal.

Segue abaixo o Quadro 2, que traz a avaliação dos informantes do corpus 1, quanto aos recursos vocais.

Quadro 2. Recursos vocais dos informantes do estudo 01 (corpus 1), segundo a avaliação dos juízes.

\begin{tabular}{|c|c|c|c|}
\hline Variáveis & $\begin{array}{c}\text { Ajustes empregados } \\
\text { pelo Inf. 1 }\end{array}$ & $\begin{array}{c}\text { Ajustes empregados } \\
\text { pelo Inf. 2 }\end{array}$ & $\begin{array}{c}\text { Ajustes empregados } \\
\text { pelo Inf. 3 }\end{array}$ \\
\hline Uso da ênfase & Restrito & Restrito & Restrito \\
\hline Uso de pausas & $\begin{array}{c}\text { Predominantemente } \\
\text { adequado }\end{array}$ & Reduzido & Adequado \\
\hline Curva melódica & $\begin{array}{c}\text { Descendente, } \\
\text { sobretudo ao final } \\
\text { das frases }\end{array}$ & $\begin{array}{c}\text { Descendente, } \\
\text { sobretudo ao final das } \\
\text { frases }\end{array}$ & $\begin{array}{c}\text { Descendente, } \\
\text { sobretudo ao final } \\
\text { das frases }\end{array}$ \\
\hline Ritmo & Adequado & Monótono & Monótono \\
\hline
\end{tabular}

Fonte: Adaptado de Carvalho, Araújo e Magalhães (2013).

Os recursos vocais dão vida à locução, considerando que é a partir deles que o audiodescritor passa emoção para sua locução. Esta, por sua vez, deve dialogar

1. "Fonação modal" refere-se ao ajuste laríngeo que geralmente utilizamos em nossa fala habitual. 
com as nuances da obra. De acordo com a avaliação dos juízes, todos os informantes fazem uso restrito da ênfase, o que pode influenciar na fruição das PcDVs e na relação do espectador com a obra, assim como também pode influenciar diretamente no ritmo da locução da AD. Isso fica evidente ao verificarmos que, pelo menos dois informantes (Inf. 2 e Inf. 3) possuem um ritmo monótono. Com relação ao uso de pausas, apenas um dos informantes (Inf. 2) apresentou um número reduzido de pausas. Por fim, a curva melódica é outro elemento que necessita ser aperfeiçoado pelos informantes, posto que todos eles apresentaram curva melódica descendente, o que pode impor para a locução da AD um ritmo, muitas vezes, cadenciado e desinteressante para o espectador.

Após a análise do corpus 1, passaremos para a análise dos informantes do corpus 2. Seguem abaixo, no Quadro 3, as avaliações dos juízes quanto à qualidade vocal dos informantes.

Ainda que os juízes avaliadores não tenham seguido o protocolo da mesma forma que aconteceu na avaliação do corpus 1, os dados encontrados foram de extrema importância para estabelecermos um paralelo entre as duas avaliações.

Ao analisarmos as avaliações, percebemos uma série de problemas relacionados, tanto com a ausência de um aperfeiçoamento e de um trabalho com a voz, quanto com a familiaridade dos informantes com a locução da AD. Os problemas partiram de uma fonação crepitante, soprosa e áspera, além de ressonância hipernasal. Revelaram um pitch entre grave e excessivamente agudo, os quais não dialogavam com a proposta da obra. Apresentaram um loudness que variou entre muito fraco e muito forte, que prejudicam o desenvolvimento de uma locução na $\mathrm{AD}$.

Quadro 3. Qualidade vocal dos informantes do estudo 01 (corpus 2), segundo a avaliação dos juízes.

\begin{tabular}{|c|c|c|c|c|c|}
\hline Variáveis & $\begin{array}{c}\text { Ajustes } \\
\text { empregados } \\
\text { pelo Inf. A }\end{array}$ & $\begin{array}{c}\text { Ajustes } \\
\text { empregados } \\
\text { pelo Inf. B }\end{array}$ & $\begin{array}{c}\text { Ajustes } \\
\text { empregados } \\
\text { pelo Inf. C }\end{array}$ & $\begin{array}{c}\text { Ajustes } \\
\text { empregados } \\
\text { pelo Inf. D }\end{array}$ & $\begin{array}{c}\text { Ajustes } \\
\text { empregados } \\
\text { pelo Inf. E }\end{array}$ \\
\hline Fonação & Crepitante & Soprosa & $\begin{array}{c}\text { Não } \\
\text { informado }\end{array}$ & Áspera & $\begin{array}{c}\text { Não } \\
\text { informado }\end{array}$ \\
\hline Ressonância & $\begin{array}{c}\text { Não } \\
\text { informado }\end{array}$ & $\begin{array}{c}\text { Não } \\
\text { informado }\end{array}$ & Hipernasal & $\begin{array}{c}\text { Não } \\
\text { informado }\end{array}$ & $\begin{array}{c}\text { Não } \\
\text { informado }\end{array}$ \\
\hline Pitch & Grave & Grave & $\begin{array}{c}\text { Muito } \\
\text { agudo }\end{array}$ & Grave & Grave \\
\hline Loudness & Fraco & Muito forte & Muito fraco & Muito forte & Forte \\
\hline Articulação & Imprecisa & Imprecisa & Imprecisa & Imprecisa & $\begin{array}{c}\text { Não } \\
\text { informado }\end{array}$ \\
\hline
\end{tabular}




\begin{tabular}{|c|c|c|c|c|c|}
\hline $\begin{array}{c}\text { Velocidade } \\
\text { da fala }\end{array}$ & Acelerada & Lenta & $\begin{array}{c}\text { Não } \\
\text { informado }\end{array}$ & $\begin{array}{c}\text { Não } \\
\text { informado }\end{array}$ & Acelerada \\
\hline CPFA & Inadequada & $\begin{array}{c}\text { Não } \\
\text { informado }\end{array}$ & Inadequada & Inadequada & $\begin{array}{c}\text { Não } \\
\text { informado }\end{array}$ \\
\hline Ataque Vocal & $\begin{array}{c}\text { Não } \\
\text { informado }\end{array}$ & $\begin{array}{c}\text { Não } \\
\text { informado }\end{array}$ & $\begin{array}{c}\text { Não } \\
\text { informado }\end{array}$ & Brusco & Brusco \\
\hline
\end{tabular}

Fonte: Adaptado de Carvalho, Araújo e Magalhães (2013).

Os dados também revelaram uma articulação predominantemente imprecisa, em alguns casos prejudicando o que está sendo enunciado. Uma velocidade da fala que variou entre lenta e acelerada, considerada prejudicial ao entendimento da AD. Uma CPFA predominantemente inadequada, revelando, algumas vezes, uma fala entrecortada pelas pausas de respiração e, por fim, um ataque vocal brusco.

No que diz respeito aos recursos vocais, todas as variáveis foram utilizadas de modo inadequado pelos informantes para a locução da AD de um filme.

Os resultados desta pesquisa apontaram, primeiramente, uma diferença entre os dois grupos, o que nos revela uma diferença entre pesquisadores que trabalham com a locução e os que fazem uso profissional da voz em relação aos pesquisadores de mestrado e doutorado, que, provavelmente, trabalham pouco com a locução na $\mathrm{AD}$ e que não fazem uso profissional da voz.

A avaliação dos juízes fonoaudiólogos sinaliza para a necessidade do trabalho da voz/fala do audiodescritor, ainda que os informantes do corpus 1 tenham se saído um pouco melhor que os informantes do corpus 2, o que já era até esperado, posto que a prática e as atividades com $\mathrm{AD}$ eram mais recorrentes no primeiro grupo.

É importante ressaltar que os resultados desta pesquisa comprovam que não basta ser estudante ou apenas pesquisador em AD para executar uma boa locução de $\mathrm{AD}$, a prática, as pesquisas e o aperfeiçoamento da voz/fala, juntos, aproximam o audiodescritor de um bom resultado.

\section{ESTUDO 02: A LOCUÇÃO NA AUDIODESCRIÇÃO PARA PESSOAS COM DEFI- CIÊNCIA VISUAL: UMA PROPOSTA PARA A FORMAÇÃO DE AUDIODESCRITO- RES - LOAD}

A segunda pesquisa revela os primeiros resultados encontrados pelo projeto LOAD. O projeto analisou, em sua fase descritiva, os trechos das locuções de ADs dos filmes Uma Vela para Dario e Entrevista produzidas pelo grupo LEAD (Legendagem e Audiodescrição) da UECE. Foram identificadas as variáveis relacionadas à 
qualidade vocal e aos recursos vocais da locução dos filmes importantes para a $\mathrm{AD}$ de filmes e para a formação de audiodescritores. As seguintes variáveis foram analisadas: fonação, ressonância, loudness, articulação, velocidade de fala, CPFA, ataque vocal, uso de ênfases, uso de pausas, curva melódica e ritmo.

No que diz respeito à qualidade vocal das locuções, seguem os resultados encontrados, conforme apresentamos nos Quadros 4 e 5.

Quadro 4. Qualidade vocal dos informantes de 1 a 4 do estudo 02 , segundo a avaliação dos juízes.

\begin{tabular}{|c|c|c|c|c|}
\hline Variáveis & $\begin{array}{c}\text { Ajustes } \\
\text { empregados } \\
\text { pelo Inf. 1 }\end{array}$ & $\begin{array}{c}\text { Ajustes } \\
\text { empregados } \\
\text { pelo Inf. 2 }\end{array}$ & $\begin{array}{c}\text { Ajustes } \\
\text { empregados } \\
\text { pelo Inf. 3 }\end{array}$ & $\begin{array}{c}\text { Ajustes } \\
\text { empregados } \\
\text { pelo Inf. 4 }\end{array}$ \\
\hline Fonação & Modal & Soprosa & Modal & Áspera \\
\hline Ressonância & Equilibrado & Laringofaríngea & Laringofaríngea & Laringofaríngea \\
\hline Loudness & Fraco & Fraco & Médio & Fraco \\
\hline Articulação & Imprecisa & Imprecisa & Precisa & Imprecisa \\
\hline Velocidade de fala & Acelerada & Acelerada & Acelerada & Lenta \\
\hline CPFA & Adequada & Adequada & Adequada & Adequada \\
\hline Ataque Vocal & Não & Não informado & Não informado & Não informado \\
\hline & informado & & & \\
\hline
\end{tabular}

Fonte: Adaptado de Araújo, Carvalho e Praxedes Filho (2013).

Os resultados encontrados, no que tange à qualidade vocal dos informantes do Projeto LOAD, reforçam a ideia de que a voz/fala dos audiodescritores necessita ser trabalhada e ajustada por meio de um programa de aperfeiçoamento da voz.

Quadro 5. Qualidade vocal dos informantes de 5 a 8 do estudo 02 , segundo a avaliação dos juízes.

\begin{tabular}{|c|c|c|c|c|}
\hline Variáveis & $\begin{array}{c}\text { Ajustes } \\
\text { empregados } \\
\text { pelo Inf. 5 }\end{array}$ & $\begin{array}{c}\text { Ajustes } \\
\text { empregados } \\
\text { pelo Inf. 6 }\end{array}$ & $\begin{array}{c}\text { Ajustes } \\
\text { empregados } \\
\text { pelo Inf. 7 }\end{array}$ & $\begin{array}{c}\text { Ajustes } \\
\text { empregados } \\
\text { pelo Inf. 8 }\end{array}$ \\
\hline Fonação & Modal & $\begin{array}{c}\text { Modal, com } \\
\text { ruídos de } \\
\text { nasalização }\end{array}$ & Soprosidade & Soprosidade \\
\hline & & & & Laringofaríngea \\
\hline Ressonância & Laringofaríngea & Hipernasal & Hipernasal & Langen \\
\hline & & & & \\
\hline
\end{tabular}




\begin{tabular}{|c|c|c|c|c|}
\hline Loudness & Fraco & Médio & Fraco & Médio \\
\hline Articulação & Imprecisa & Precisa & Precisa & Precisa \\
\hline Velocidade da fala & Acelerada & Média & Acelerada & Acelerada \\
\hline CPFA & Adequada & Adequada & Adequada & Adequada \\
\hline Ataque Vocal & Não informado & $\begin{array}{c}\text { Não } \\
\text { informado }\end{array}$ & Não informado & Não informado \\
\hline & & & & \\
\hline
\end{tabular}

Fonte: Adaptado de Araújo, Carvalho e Praxedes Filho (2013).

Sobre a avaliação, é importante destacar que para a variável pitch não houve ocorrências significativas, apenas o Inf. 8 apresentou um pitch mais grave do que o seu natural, o que pode representar uma tensão na emissão. No que diz respeito às demais variáveis, algumas considerações necessitam ser feitas, como o fato de a maioria dos informantes apresentarem uma ressonância laringofagíngea, que pode levar ao abafamento da produção da voz/fala e à diminuição da projeção vocal e da fala, o que, por sua vez, pode prejudicar a recepção da AD.

Com relação à articulação, os informantes apresentaram ajustes alterados na precisão articulatória, como, por exemplo, distorções principalmente no tepe alveolar vozeado e falta de firmeza articulatória (Inf. 1), má articulação ao final da elocução e sobrearticulação (Inf. 4), fala acelerada (Inf. 2), articulação travada ou reduzida (Inf. 5). Isso denota um descontrole dos informantes sobre esta variável, considerada uma das mais importantes. Um problema nesta variável pode comprometer o que está sendo dito, bem como o entendimento das PcDVs.

Para a variável velocidade de fala, os informantes, em sua maioria, apresentaram uma locução acelerada, o que pode comprometer a locução ou impedir que as inflexões cumpram o seu papel. O Inf. 4 apresentou velocidade lenta, o que também pode comprometer a locução. Como podemos perceber essa variável interfere diretamente na questão da inteligibilidade do texto falado, o que pode refletir no processo de recepção por parte da PcDV.

Com relação aos recursos vocais das locuções, seguem abaixo os resultados encontrados:

- Uso de ênfase: todos os participantes apresentaram um ajuste "restrito", sendo que o Inf. 1 foi caracterizado pela ausência quase completa de ênfase; o Inf. 2 apresentou uma limitação do uso da ênfase em função da soprosidade; o Inf. 3 apresentou monotonia; o Inf. 4 apresentou uma suave expressividade; o Inf. 5 foi caracterizado pela falta de expressividade; o Inf. 6 empregou inadequadamente 
a ênfase com tendência à suavidade; o Inf. 7 apresentou uma ênfase que não acompanhava a expressividade exigida pelas cenas; e o Inf. 8 apresentou pouca expressividade, não colaborando para a dramaticidade do filme.

- Uso de pausas: todos apresentaram ajuste adequado.

- Curva melódica e Ritmo: todos apresentaram ajuste inadequado.

De acordo com os dados encontrados nessa etapa, foi preparada a etapa seguinte, fase exploratória do projeto, na qual aconteceu um curso que tinha como objetivo adequar os recursos de locução e interpretação ao trabalho da audiodescrição de filmes, bem como refazer a audiodescrição dos filmes com base nos resultados encontrados e sob a orientação do fonoaudiólogo. Esta fase contou ainda com uma pesquisa de recepção com PcDVs para avaliação do público-alvo das locuções feitas antes e após o curso.

Durante o curso, foram estabelecidos parâmetros para a locução de AD, tais como: qualidade vocal adaptada ao produto audiodescrito, realização de atividades de relaxamento vocal, aquecimento vocal, respiração para a locução, nitidez articulatória, recursos de expressividade e práticas em locução em audiodescrição.

O resultado desse processo foi uma maior fluidez na produção da fala, redução de ruídos como pigarros, rouquidão, soprosidade, entre outros, e uma melhor expressividade na leitura dos roteiros.

Ainda no curso, critérios de escolha do tipo de locução que melhor se adequava às obras audiodescritas foram criados através das práticas de locução, tais como pitch, loudness, velocidade de fala, marcadores regionais de variação linguística, qualidade da voz, relação harmônica entre texto e voz. Alguns exemplos foram destacados, como o fato de vozes mais agudas serem mais adequadas para aos filmes infantis e comédias, ou ainda vozes roucas e fracas podem passar a sensação de cansaço e estresse para o ouvinte.

A etapa seguinte compreendeu o julgamento perceptual-auditivo do grupo de PcDVs. A coleta foi realizada individualmente no LATAV e compreendia as seguintes fases: a) assinatura do Termo de Consentimento Livre e Esclarecido pelo participante, concordando em participar da pesquisa; b) participante assistia a cada um dos trechos das ADs dos filmes gravadas, antes e após o curso de locução; c) o participante respondia às perguntas do protocolo de pesquisa. Como resultado tivemos uma preferência das $\mathrm{PcDV}_{\mathrm{s}}$ pela versão mais expressiva (versão reaudiodescrita) em detrimento da primeira AD produzida pelo LEAD. Como afirmou um dos participantes PcDV, "o timbre de voz é diferente e a maneira de falar da segunda tá um pouco mais natural, a primeira tá muito técnica" (PcDV 1), que corrobora a preferência pela versão reaudiodescrita. 
Os resultados da segunda pesquisa confirmaram as hipóteses reveladas a partir dos resultados encontrados na primeira pesquisa. O trabalho feito com os audiodescritores revelou um avanço e uma quebra de paradigmas com relação à locução da AD. Isso fica evidente na escolha das PcDVs. Fica claro, no comentário destacado acima, que havia uma preocupação com a técnica, mas que não havia um cuidado com a expressividade da locução.

A análise feita pelos juízes na primeira etapa do projeto LOAD corroboraram os resultados encontrados na primeira pesquisa, além de ressaltaram dois importantes pontos a serem trabalhados na locução da AD: a curva melódica e o ritmo.

Ainda em decorrência dos estudos desenvolvidos no LOAD, posteriormente às atividades há pouco mencionadas, foi publicado capítulo de livro em que se propõe parâmetros sistemáticos para a locução na audiodescrição (PALMEIRA; ARAÚJO; CARVALHO, 2016). Além disso, tais estudos forneceram subsídios para o desenvolvimento do projeto de tese "Um estudo sobre a locução da audiodescrição de Miralu e a Luneta Encantada" (LEÃO, 2017), ora em andamento, cujos resultados parciais são apresentados a seguir, que analisa quais aspectos da locução propostos no LOAD devem ser considerados relevantes para a audiodescrição de peças teatrais.

\section{ESTUDO 03: UM ESTUDO SOBRE A LOCUÇÃO DA AUDIODESCRIÇÃO DE MI- RALU E A LUNETA ENCANTADA}

A terceira pesquisa (LEÃO, 2017), que ainda se encontra em andamento, possui apenas os resultados das análises dos juízes. Ela contou com a participação de 02 pesquisadores do grupo LEAD, os quais já participaram da primeira coleta de locução, ambos não têm experiência com o uso profissional da voz. Três juízes fonoaudiólogos avaliaram as gravações e não houve nenhuma preparação vocal dos audiodescritores, além do curso promovido através do projeto LOAD.

O diferencial desta pesquisa é que, como se trata de uma locução para o teatro, a narração foi feita ao vivo e captada no momento em que os audiodescritores estavam realizando a locução, durante a apresentação do espetáculo. Cabe destacar que se trata da $\mathrm{AD}$ de um espetáculo infantil e que se esperava que a locução tivesse um diferencial para este público, sobretudo com relação ao ritmo e à curva melódica. Quadro 6 - Qualidade vocal dos informantes do estudo 03, segundo a avaliação dos juízes. 


\begin{tabular}{|c|c|c|}
\hline Variáveis & Ajustes empregados pelo Inf. 1 & Ajustes empregados pelo Inf. 2 \\
\hline & & \\
\hline Fonação & Modal & Modal \\
\hline Ressonância & Equilibrada & Hipernasal leve \\
\hline Pitch & Mediano à grave & Médio \\
\hline Loudness & Satisfatória & Fraco \\
\hline Articulação & Precisa & Precisa \\
\hline Velocidade da fala & Acelerada & Acelerada \\
\hline CPFA & Adequada & Adequada \\
\hline & Isocrônico & Isocrônico \\
\hline Ataque Vocal & & \\
\hline
\end{tabular}

Fonte: Leão (2017)

Os resultados preliminares, encontrados na análise da terceira pesquisa, apresentados no Quadro 6, corroboram, em relação a algumas variáveis, os resultados revelados nas pesquisas anteriores, ainda que os audiodescritores tenham passado pelo aperfeiçoamento realizado pelo Projeto LOAD. Contudo, são necessárias algumas ponderações sobre os resultados encontrados, como o fato de os informantes apresentarem fonação modal, mas com sinais claros de voz áspera e também soprosidade, o que pode estar relacionado à pouca resistência vocal ou a ausência de uma conscientização vocal antes da realização da locução.

O pitch, desta vez, aproximou-se do que era esperado para o gênero e não tivemos problemas com essa variável, o que não aconteceu nas pesquisas anteriores. O Inf. 2 chegou a apresentar um pitch levemente agudo no início da locução, mas no decorrer da apresentação a loudness diminuiu e, com isso, o pitch se ajustou. Já a loudness caiu em alguns momentos, mas esteve satisfatória na maior parte do tempo para o Inf. 1; para o Inf. 2, a loudness, em alguns momentos, foi considerada muito fraca, o que pode ter ocorrido tanto em função da captação do áudio, como em função da ausência de familiaridade do locutor audiodescritor com o microfone do transmissor.

No que diz respeito à articulação, esta foi considerada precisa para o Inf. 1, ainda que alguns sons oclusivos tenham sido produzidos com ruídos, o que pode ter sido ocasionado pela qualidade do microfone; para o Inf. 2, ainda que a articulação tenha sido considerada precisa, em alguns momentos, devido à loudness fraca, algumas variáveis sofreram interferência, sobretudo a articulação ao final das palavras, que não foi considerada satisfatoriamente clara. Ainda sobre a variável articulação, um dos 
juízes destacou que o aumento da velocidade, em alguns momentos, fez com que a precisão da articulação diminuísse, o que pode ter sido ocasionado pelo excesso de texto na inserção ou uma não adequação do texto da $\mathrm{AD}$ ao ritmo da locução do locutor audiodescritor.

Para a variável velocidade, ainda permanecemos com os mesmos resultados das análises anteriores, uma velocidade predominantemente rápida, contudo os juízes informaram que a articulação foi preservada. Sobre a CPFA, tivemos um bom controle dos informantes, considerando que estes realizaram adequadamente a coordenação entre respiração, fonação e articulação, contudo os juízes ressaltaram que as frases usadas eram curtas, o que pode ter favorecido a CPFA. $\mathrm{O}$ ataque vocal foi considerado isocrônico, caracterizado como suave, equilibrado ou normal.

Sobre os recursos vocais, para o Inf. 1, tivemos uso restrito das ênfases (agudização e alongamento de vogais) e uso adequado das pausas, contudo, de um modo geral, as frases eram curtas. Houve a presença apenas de pausas respiratórias. A curva melódica foi predominantemente descendente, com uma discreta variação. Houve preponderância do ritmo monótono, o que pode comprometer a dramaticidade da cena teatral e interferir sobremaneira na fruição dos PcDVs.

Para o Inf. 2, no que tange aos recursos vocais, temos o uso de ênfases restrito, não há expressividade na locução, sem nuances de pitch ou loudness, apenas variação na velocidade, mas sem a devida intenção. $\mathrm{O}$ uso das pausas foi considerado adequado, contudo um dos juízes destacou que, de um modo geral, as frases eram curtas e que houve a presença apenas de pausas respiratórias. A curva melódica ocorreu predominantemente de forma descendente, com uma locução "sem brilho" e linear (sem contornos melódicos). O uso dos recursos vocais foi muito restrito, com ritmo quase monótono, não sendo completamente monótono devido à pouca variação na velocidade.

Os resultados da avaliação dos recursos vocais corroboram os resultados das avaliações anteriores, sobretudo com relação ao uso de ênfases, curva melódica e ritmo, contudo não sabemos precisar se isso ocorreu em função de a locução ter sido realizada ao vivo, o que poderia ter sido avaliado por meio de um relato livre do audiodescritor após a experiência, no qual o mesmo informaria sobre as suas dificuldades em realizar a locução numa modalidade ao vivo.

Algumas considerações com relação a essa modalidade de $\mathrm{AD}$ devem ser ressaltadas, como o fato de o locutor audiodescritor diminuir um pouco a intensidade da voz em função do uso do microfone do transmissor, talvez para não causar estranhamento ao espectador (isso foi percebido ao gravarmos algumas locuções de eventos ao vivo), no entanto, tal procedimento não se faz necessário, 
pois os receptores utilizados pelas PCDVs possuem uma graduação de volume, que pode ser alterada por eles, mediante sua preferência.

Com a realização deste terceiro estudo, percebemos que, mesmo com a preparação dos audiodescritores com o curso do projeto LOAD, há ainda um reflexo do "habitus vocal" criado em torno da locução da AD, com predomínio de uma locução sem inflexões e com curva melódica descendente, sobretudo ao final das inserções de AD. Talvez isso aconteça devido à ausência de preparação dos audiodescritores antes da locução ao vivo. Sendo assim, se faz necessário pensar em uma proposta de treinamento vocal para a locução de um espetáculo de teatro que leve em conta as especificidades de um evento ao vivo, como o local de onde é transmitida a locução, os equipamentos utilizados e a tensão que envolve esse tipo de locução.

Cabe destacar, que esse estudo ainda se encontra em andamento e que será realizado um treinamento com os audiodescritores, uma nova locução após esse treinamento e, em seguida, uma avaliação da locução por PcDVs.

\section{CONCLUSÕES}

Ao realizarmos, neste artigo, a descrição e a análise dos três estudos sobre locução na audiodescrição, gostaríamos de ressaltar a importância da necessidade de desenvolvimento contínuo de pesquisas sobre audiodescrição, em especial acerca do papel da locução na AD. A partir dos estudos empreendidos por Carvalho, Araújo e Magalhães (2013), e, em seguida, por meio do projeto LOAD (ARAÚIJO; CARVALHO; PRAXEDES FILHO, 2013), que dá continuidade a esse processo de investigação, que agora está se expandindo para outras modalidades de AD, conforme sinalizamos no terceiro estudo analisado (LEÃO, 2017), é possível perceber que os autores vêm repensando e reformulando a prática da AD no Brasil, sem deixar de lado o diálogo direto com as PcDVs, público alvo desses estudos.

Este artigo revela ainda a importante contribuição da Fonoaudiologia para o desenvolvimento das pesquisas em AD, a partir da avaliação das vozes por parte de juízes fonoaudiólogos e da capacitação de locutores audiodescritores, a fim de aperfeiçoar a locução e encontrar parâmetros que auxiliem os audiodescritores a trabalharem a sua voz/fala de forma profissional e condizente com a obra audiodescrita.

As análises realizadas nos três estudos descritos revelam que algumas práticas ainda são recorrentes na locução em audiodescrição e vêm reforçar pontos importantes que necessitam de um trabalho mais aprofundado, principalmente com 
relação aos recursos vocais, uma vez que os audiodescritores continuam tendo dificuldade em trabalhar variáveis como o uso da ênfase, a curva melódica e o ritmo.

Ressaltamos, ainda, a importância do diálogo e das discussões entre os campos da Tradução Audiovisual e da Fonoaudiologia, para que pesquisas sejam fomentadas em todas as áreas de atuação da $\mathrm{AD}$, uma vez que esta modalidade de tradução vem se expandindo cada vez mais e exigindo dos profissionais de AD uma especificidade maior no seu trabalho, sobretudo no que diz respeito ao uso da voz/ fala. Como exemplo, podemos citar a AD de futebol, que possui uma forma de narrar extremamente específica.

Por fim, destacamos a valiosa contribuição das PcDVs para o aperfeiçoamento deste serviço, pois é a partir da validação desse público que conseguiremos repensar a nossa prática e promover acessibilidade audiovisual com qualidade e de forma ampla.

\section{REFERÊNCIAS BIBLIOGRÁFICAS}

ARAúJJ, V. L. S.; CARVALHO, W.J. de A.; PRAXEDES FILHO, P.H.L. (2013). A locução na audiodescrição para pessoas com deficiência visual: uma contribuição à formação de audiodescritores. Projeto de pesquisa. Programa de Pós-Graduação em Linguística Aplicada, Universidade Estadual do Ceará, Fortaleza.

BARROS FILHO, C. (2005). A construção social da voz. In: Kyrillos, L. R. (org.). Expressividade: da teoria à prática. Rio de Janeiro: Revinter, pp. 27-42.

BENECKE, B. (2004). Audio-Description. Meta: Journal des traducteurs. v. 49, $\mathrm{n}^{\circ} 1$, pp. 78-80. Disponível em: https://www.erudit.org/fr/revues/meta/2004-v49-n1meta733/009022ar/. Acesso em: 13 abr. 2016.

BEHLAU, M.; MADAZIO, G.; FEIJÓ, D.; PONTES, P. (2001). Avaliação de voz. In: BEHLAU, M. (org.). Voz: o livro do especialista. São Paulo: Revinter, v. I, pp. 85-245.

BEHLAU, M, FEIJÓ, D.; MADAZIO, G.; REHDER, M.I.; AZEVEDO, R.; FERREIRA, A.E. (2005). Voz profissional: aspectos gerais e atuação fonoaudiológica. In: Behlau, M. (org.). Voz: o livro do especialista. São Paulo: Revinter, v. II, pp. 288-407.

CARVALHO, W.J. de A.; MAGALHÃES, C.; ARAÚJO, V.L.S. (2013). Locução em filmes audiodescritos para pessoas cegas ou com baixa visão: uma contribuição à formação de audiodescritores. In: ARAÚJO, V.L.S.; ADERALDO, M.F. Os novos rumos da pesquisa em audiodescrição no Brasil. Curitiba: CRV, pp.151-168. 
CASADO, A.B. (2007). Directores em La sombra: personajes y su caracterización em el guión audiodescrito de "Todo sobre mi madre". In: Jimenéz Hurtado, C. Traducción y acessibilidad. Subtitulación para sordos y audiodescripción para ciegos: nuevas modalidades de traducción audiovisual. Frankfurt: Peter Lang, 2007, pp. 133-152.

CASSOL, M; BEHLAU, M; MADUREIRA, S. (2001). Aplicação de um modelo fonético na análise da qualidade vocal de indivíduos disfônicos. In: Behlau, M. (org.). Voz: o livro do especialista. São Paulo: Revinter, v.I, pp. 85-108.

FRANCO, E.; ARAÚJO, V. S. (2011). Questões terminológico-conceituais no campo da tradução audiovisual. Tradução em Revista. no 11, p. 1-23. Disponível em: <http:// www.maxwell.lambda.ele.puc-rio.br/trad_em_revista.php? strSecao $=$ input $0>$. Acesso em: 13 abr. 2016.

GAMBIER, Y. (2003). Screen Transadaption: perception and reception. The Translator. Manchester: St. Jerome, Special Edition on Screen Translation, v. 9, $\mathrm{n}^{\mathrm{o}} 2$, p. 171-189. Disponível em: <http://www.stjerome.co.uk/periodicals/journal. php? $j=72 \& v=135 \& i=139>$. Acesso em: 13 abr. 2016.

GAMBIER, Y. (2004). La traduction audiovisuelle: un genre en expansion. Meta: Journal des traducteurs. v. 49, $\mathrm{n}^{\circ} 1$, pp. 1-11. Disponível em: < http://id.erudit.org/ iderudit/009015ar>. Acesso em: 13 abr. 2016.

JAKOBSON, R. (1995). Linguística e comunicação. São Paulo: Cultrix.

JIMÉNEZ-HURTADO, C. (2007). Una gramática local del guión audiodescrito. Desde la semántica a la pragmática de nuevo tipo de traducción. In: Hurtado, C. J. Traducción y accessibilidad: subtitulación para sordos y audiodescripción para ciegos: nuevas modalidades de traducción audiovisual. Amsterdã: Peter Lang, pp. 55-80.

KYRILLOS, L. (2005). Expressividade: da teoria à prática. Rio de Janeiro: Revinter, 2005.

LAVER, J. (1980). The phonetic description of voice quality. London: Cambridge University Press.

LEÃO, B. A. (2017). Um estudo sobre a locução da audiodescrição de Miralu e a Luneta Encantada. Tese de Doutorado em Linguística Aplicada (em andamento). Programa de PósGraduação em Linguística Aplicada, Universidade Estadual do Ceará, Fortaleza.

PALMEIRA, C. T.; ARAÚJO, V. L. S.; CARVALHO, W. J. de A. (2016). Locução para audiodescritores: contribuições da fonoaudiologia. In: ADERALDO, M. F.; MASCARENHAS, R. de O.; ARAÚJO, V. L. S.; DANTAS, J. F. de L. Pesquisas teóricas $e$ aplicadas em audiodescrição. Natal, RN: EDUFRN. Disponível em: http://www.sedis. 
ufrn.br/bibliotecadigital/site/interativos/pesquisa-teorica-aplicada/PesqTeoricasAplicadasAudiodescricao_FINAL-27MAR2017epub.epub. Acesso em: 7 ago. 2017.

PLAZA, J. (1987). Tradução intersemiótica. São Paulo: Perspectiva.

MATAMALA, A. La audiodescripción en directo (2007). In: Jiménez-Hurtado, C. Traducción y accesibilidad. Subtitulación para sordos y audiodescripción para ciegos: nuevas modalidades de Traducción Audiovisual. Amsterdã: Peter Lang, pp. 121-132.

MADUREIRA, S. Expressividade da fala (2005). In: Kyrillos, L.R. (org.). Expressividade: da teoria à prática. Rio de Janeiro: Revinter, pp.15-25.

FARIAS, S.; NEVES, J. (2014). Audiodescrição e poética da linguagem cinematográfica: elementos para outras abordagens. In: Cardoso, E.; Cuty, J. (eds). Acessibilidade em ambientes culturais. Relatos de experiências. Porto Alegre: Marcavisual, pp. 80-101.

SANTIAGO, S.M.S.A. (2015). Audiodescrição em contexto de teatro em Portugal. Dissertação de Mestrado em Tradução e Serviços Linguísticos. Faculdade de Letras da Universidade do Porto, Porto. Disponível em: < https://repositorio-aberto.up.pt/ handle $/ 10216 / 6815 /$ browse type $=$ author\&order $=$ ASC\&rpp $=40 \&$ value $=$ Sandra + Maria+Sanches+Alves+Santiago > . Acesso em: 9 mar. 2016.

SNYDER, J. (2008). Audiodescription - the visual made verbal. In: Díaz Cintas, J. (ed). The didactics of Audiovisual Translation. Amsterdam: John Benjamins, pp. 191-198.

SILVA, M.C.C.C.da. (2009). Com os olhos do coração: estudo acerca da audiodescrição de desenhos animados para o público infantil. Dissertação de Mestrado em Letras e Linguística. Programa de Pós-Graduação em Letras e Lingüística, Universidade Federal da Bahia, Salvador.

Recebido: $18 / 05 / 2017$

Aceito: 13/08/2017 